\title{
Experimental study on flexural performance of fabricated ceramsite concrete lightweight Wall Panel
}

\author{
Bu Changming ${ }^{1,2}$, Yang Haiyan ${ }^{1,2,}$, Sun $\mathrm{Yi}^{1,2}$, Liu Hongzhi ${ }^{1,2}$, Zhu Dongxu ${ }^{1,2}$, Liu Lei ${ }^{1,2}$, \\ and Wang Faxiang ${ }^{3}$ \\ ${ }^{1}$ School of Civil Engineering and Architecture, Chongqing University of Science \& Technology, \\ Chongqing 401331, China \\ ${ }^{2}$ Chongqing Key Laboratory of Energy Engineering Mechanics \& Disaster Prevention and Mitigation, \\ Chongqing 401331, China \\ ${ }^{3}$ Chongqing Chengwei Light Quality Wall Board CO.LTD
}

\begin{abstract}
In this paper, through the mechanical property test of lightweight ceramsite concrete partition board, the bending bearing capacity of different thickness of the board is measured. Through the test, the influence of humidity on the ceramsite concrete wall panel and the vertical compressive performance of the ceramsite concrete slab are studied, and the vertical compressive bearing capacity is obtained. The results show that: the bearing capacity of different thickness wallboards used in the test is far greater than 1.5 times of the dead weight of the plates. Through the failure load of the plates, the deflection values and bending stiffness values of the wallboards in the actual engineering are obtained. The vertical allowable loads of the three thickness plates are $129.73 \mathrm{KN}$, $311.90 \mathrm{KN}$ and $127.02 \mathrm{KN}$.
\end{abstract}

Keywords: lightweight Wall Panel, flexural, ceramsite

\section{Introduction}

The flexural performance of wallboard is a very important and fundamental factor. It is used as the external wall to bear a certain wind load, and used as the internal wall to bear a certain furniture load, etc., therefore, the flexural performance directly affects its application in engineering. The air humidity is an inevitable influence factor on the bending performance of wall panels. Xu Chunyi et al. [1] carried out wallboard optimization by changing the splicing form of wallboard and the area of fiber grilles, and studied the influence of corresponding optimization form on the failure form, deflection and flexural capacity of wallboard. Pan Guangdong et al. [2] found that the type and thickness of the cold-formed thin-walled steel-light polymer composite wallboard were the main factors affecting the bending performance of the wallboard through the bending test. Zhu Wenxiang et al. [3] carried out bending tests on a ribbed precast concrete insulation

\footnotetext{
${ }^{*}$ Corresponding author e-mail: 1256883904@qq.com
} 
wallboard by using the method of sandbags evenly distributed and stacked. Chen Boshan et al. [4] studied the influence of the form of internal reinforcement on the bending resistance and failure characteristics of plates. Zhou Xuejun et al. [5] carried out the flexural bearing capacity test of autoclavated concrete wall panel with autoclavated porcelain powder to study the mechanical properties of the wall panel. Su Zheng et al. [6] studied the failure characteristics, flexural bearing capacity and deformation capacity of steel mesh truss-polystyrene foam (EPS) composite board coated with expanded perlite (POE) cement mortar. Wang Yue [7] carried out flexure bearing capacity test on autoclaved porcelain powder aerated concrete wallboard, and analyzed its deformation capacity and fracture development mode. Chen $\mathrm{Bo}[8]$ carried out flexural bearing capacity test and axial compression test on assembled light steel composite insulation exterior wall panel.

A number of scholars have tested the flexural performance of various fabricated wallboards. Based on the previous research, this paper refers to the relevant test methods of the flexural capacity of lightweight wallboard (GBT 23451-2009), after curing at room temperature and high humidity, the plates with different thickness are pressurized under uniform load. Then, the influence of air humidity on the actual flexural bearing capacity of lightweight ceramsite concrete partition board is analyzed. The slab is cut into prism and tested under axial compression, the vertical allowable load of the slab is obtained by analyzing the data, which provides some theoretical basis for its application in practical engineering.

\section{Test Overview}

\subsection{Test materials and equipment}

In this paper, ceramsite concrete wallboard produced by the manufacturer is used. The wall panels are hollow, the $90 \mathrm{~mm}$ thick panel has 7 holes with the diameter of $50 \mathrm{~mm}$, the $120 \mathrm{~mm}$ thick panel has 6 holes with the hole diameter of $70 \mathrm{~mm}$, the $150 \mathrm{~mm}$ thick wallboard has 5 holes with the hole diameter of $90 \mathrm{~mm}$. The number and specification of plates required for the test are shown in Table 1.

Table 1. Specification and quantity of wallboard

\begin{tabular}{|c|c|c|}
\hline Wall panel thickness & Wall panel size $(\mathrm{L} \times \mathrm{B} \times \mathrm{h})$ & Number of tests required \\
\hline $90 \mathrm{~mm}$ & $2600 \times 600 \times 90$ & 6 \\
\hline $120 \mathrm{~mm}$ & $2000 \times 600 \times 120$ & 15 \\
\hline $150 \mathrm{~mm}$ & $2900 \times 600 \times 150$ & 6 \\
\hline
\end{tabular}

A large cutting machine is used to cut the finished boards with different thicknesses to obtain prismatic blocks. Because the ceramsite concrete slab produced by factory is hollow slab, the thickness of the slab is the square bottom side length of prism bottom surface, and the height of prism is obtained by cutting the intact cavity to the length direction of slab. The number and specifications of prisms required for the test are shown in Table 2.

Table 2. Quantity table of prism required

\begin{tabular}{|c|c|c|c|}
\hline \multirow{2}{*}{ Prism edge length } & \multicolumn{3}{|c|}{ Prism height $(\mathrm{mm})$} \\
\cline { 2 - 4 } & 400 & 500 & 600 \\
\hline $90 \mathrm{~mm}$ & 3 & 3 & 3 \\
\hline $120 \mathrm{~mm}$ & 3 & 3 & 3 \\
\hline $150 \mathrm{~mm}$ & 3 & 3 & 3 \\
\hline
\end{tabular}

The artificial climate chamber is used in the test, it is mainly composed of climate 
chamber, air conditioning system, cold and heat source system, integrated control and data acquisition system, which can be used for various temperature and humidity environment and ventilation environment simulation. The pressure test of prism was carried out by using the wow-1000h electronic universal testing machine with the range of $10 \mathrm{t}$ in the laboratory.

\subsection{Loading device}

The loading device is arranged as shown in Figure 1. A dial indicator is placed on the surface of the support plate at both ends to measure the deformation displacement of the plate end, and a dial indicator is set in the middle of the span to measure the deformation displacement of the plate in the middle of the span. The left side of the wall panel is fixed hinge support, and the right side is rolling hinge bearing (steel column with diameter of $60 \mathrm{~mm}$ ), a bearing plate is placed above the left and right supports, the bearing plate is a steel plate with width of $100 \mathrm{~mm}$ and thickness of $6 \mathrm{~mm}-15 \mathrm{~mm}$.

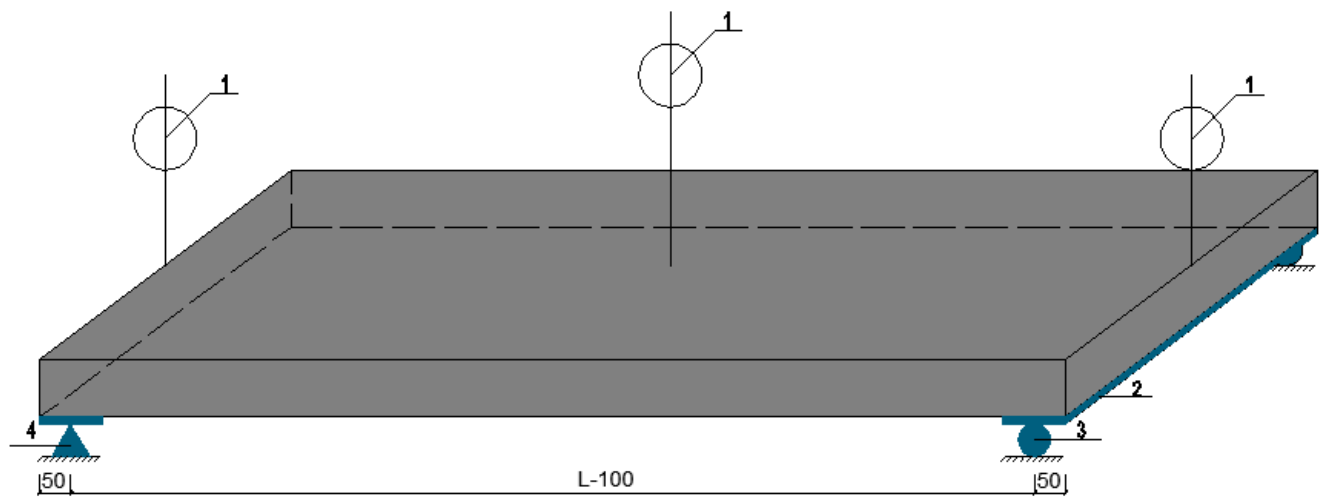

1-dial indicator,2-Pressure plate,3-roller support,4-pin support

Figure 1. Wall panel loading device

\subsection{Test process}

Three wallboards of three thicknesses are put into the artificial warehouse, three wallboards form a group, and then adjust the temperature to $20^{\circ} \mathrm{C}$ and the humidity to $80 \%$, after that, the wall panels are taken out for loading, and the actual bending load of the wallboards are measured. In order to test the influence of time on ceramsite concrete slab in high humidity environment, put the commonly used $120 \mathrm{~mm}$ thick slab into the artificial climate chamber, three slabs are placed in a group for 2 days, 3 days and 4 days, respectively, a group of plates was taken out every day to test the bending bearing capacity of the strips. In order to distinguish the slabs, the slabs are numbered, 0 stands for room temperature, 1,2,3 stand for one day, two days and three days in high humidity environment

According to the code requirements, the load shall not be less than five levels, and the load of each level shall not be greater than $30 \%$ of the dead weight of the slab, the pile length is equal, the gap is even, and the pile width is the same as the plate width. The first four stages were placed for $2 \mathrm{~min}$ after each loading stage, and the fifth stage was loaded to 1.5 times of the weight of the slab, and the standing time was $5 \mathrm{~min}$. After that, if the load is continued to be applied, it will be cycled in this way until the fracture failure. The total load from the first level load to the fifth level load (or the first level load before fracture failure) is taken as the test result.

According to the specification, the loading of each stage is about $30 \%$ of the board weight. Therefore, the $90 \mathrm{~mm}$ plate adopts $3 \mathrm{~kg}$ sandbag, $30 \mathrm{~kg}$ for each stage, $5 \mathrm{~kg}$ sandbag 
for $120 \mathrm{~mm}$ slab, $50 \mathrm{~kg}$ for each stage, and $50 \mathrm{~kg}$ for $5 \mathrm{~kg}$ sandbag for each stage

\section{Test analysis of bending resistance}

\subsection{Comparison of failure load}

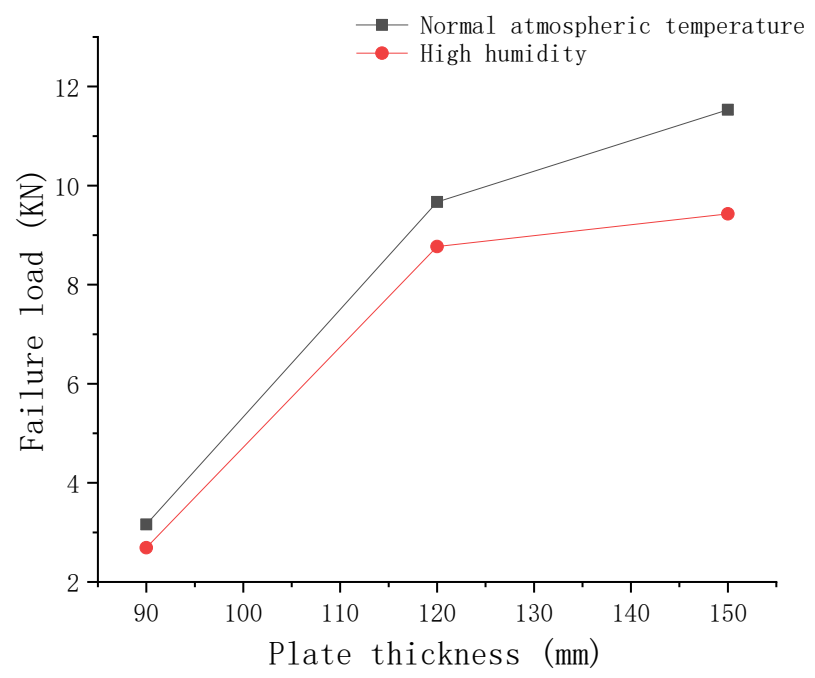

Figure 2. Comparison of failure load of slabs with different thickness

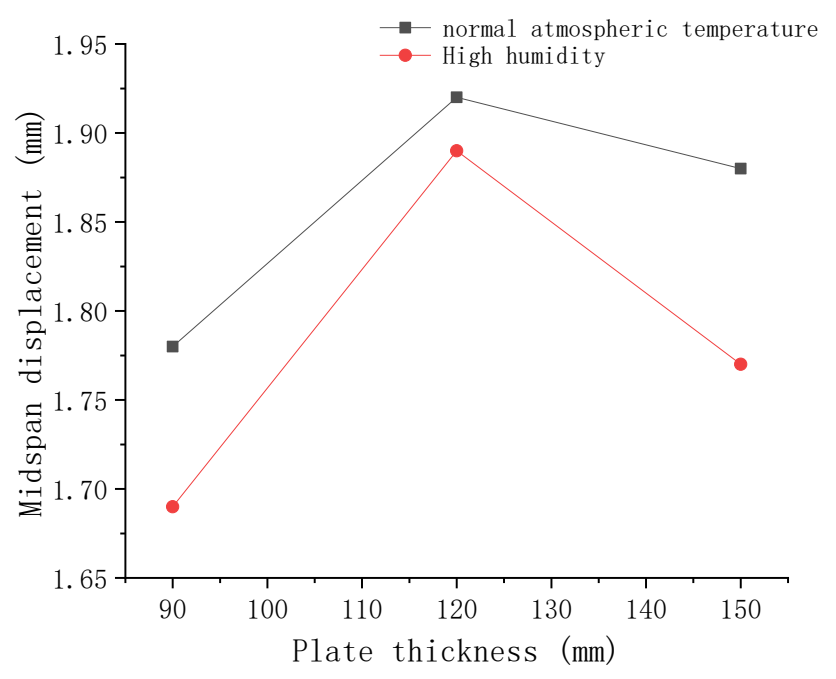

Figure 3. Comparison of midspan displacement of slabs with different thicknesses

It can be seen from Figure 2. that the thickness of the slab has a great influence on the bearing capacity of the slab. With the increase of the plate thickness, the bearing capacity of the plate increases gradually, the bearing capacity of the plate with the thickness of $120 \mathrm{~mm}$ 
increases about three times by compared with the plate with the thickness of $90 \mathrm{~mm}$, the bearing capacity of the plate with the thickness of $150 \mathrm{~mm}$ increases by about 1.2 times, through compared with that of the plate with the thickness of $120 \mathrm{~mm}$.

The average water absorption of $90 \mathrm{~mm}, 120 \mathrm{~mm}$ and $150 \mathrm{~mm}$ thick plates were $5.2 \%, 4.9 \%$ and $5.6 \%$, respectively. The flexural capacity of the plate decreased by $13.6 \%, 9.1 \%$ and $19.4 \%$ respectively, compared with that under normal temperature. Compared with the average mid span displacement of the slab at room temperature, the mid span displacement of the slab also slightly decreases, which proves that the flexural bearing capacity of the slab has a certain decline in high humidity environment, but its bearing capacity is still 1.5 times higher than the dead weight of the slab, meeting the requirements of the code.

\section{$3.2120 \mathrm{~mm}$ plate under high humidity}

By loading $120 \mathrm{~mm}$ wallboard with different curing time in high humidity environment, the load-displacement curve of $120 \mathrm{~mm}$ thick wallboard is obtained. three groups of bending bearing capacity data were obtained every different time, select the one with better test effect to draw a broken line diagram. As shown in Figure 4. below.

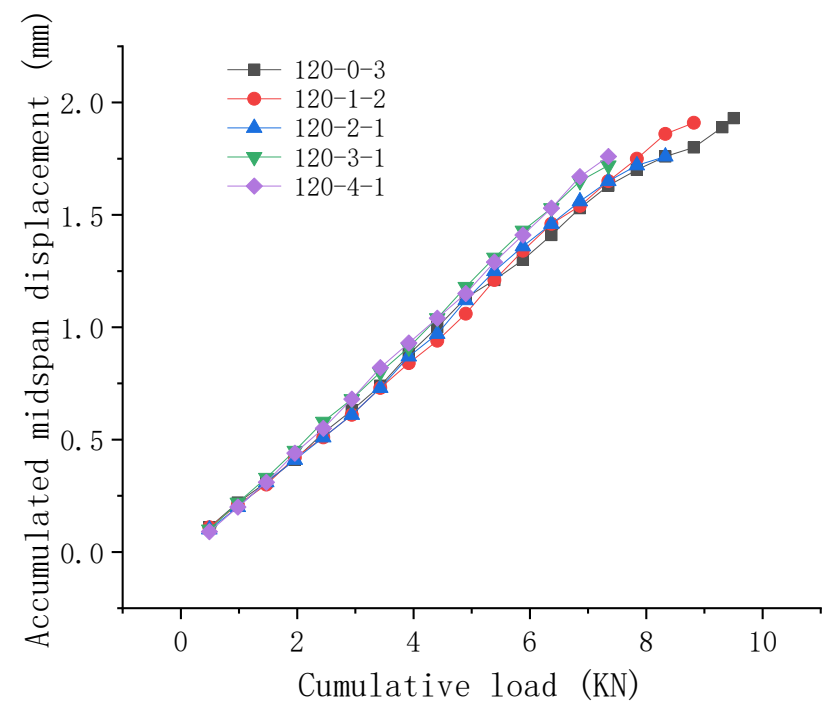

Figure 4. Load displacement diagram of slab at different time in $80 \%$ humidity environment

The load displacement curves of slab 120-0-3, slab 120-1-2, slab 120-2-1, slab 120-3-1 and slab 120-4-1 have the same shape. The failure of ceramsite concrete wallboard shows strong regularity, from the load displacement curve, it can be seen that in the initial stage of loading, the load and displacement of the wall panel are basically linear, it can be considered that the wall panel is in the elastic stage at the initial stage, and the ceramsite concrete is in good condition; With the increase of load to $6 \mathrm{KN}$, the curve begins to appear inflection point and plastic deformation occurs; With the continuous increase of load, the plastic deformation accumulates and cracks appear on the bottom and side of the wall panel, and the plastic deformation accelerates until the wall panel is damaged.

Table 3. Test data of different time plates in $80 \%$ humidity environment

\begin{tabular}{|c|c|c|c|c|}
\hline Time & number & Slabweight $(\mathrm{kg})$ & Failure load $(\mathrm{kg})$ & Midspan displacement $(\mathrm{mm})$ \\
\hline 0 & $120-0-3$ & 139.8 & 970 & 1.89 \\
\hline 1 & $120-1-2$ & 149.4 & 875 & 1.86 \\
\hline
\end{tabular}




\begin{tabular}{|l|l|l|l|l|}
\hline 2 & $120-2-1$ & 154.3 & 830 & 1.72 \\
\hline 3 & $120-3-1$ & 156.1 & 750 & 1.65 \\
\hline 4 & $120-4-1$ & 153.2 & 740 & 1.67 \\
\hline
\end{tabular}

With the increase of time, the moisture absorption of the board gradually decreases, and finally tends to be stable, because the test is not the same board, the weight of the plate in four days is smaller than that in three days, this is because the weight of the plate itself is different at room temperature. With the increase of water absorption, the flexural bearing capacity of the slab is also gradually decreasing, and the decreasing trend is becoming smaller. The mid span displacement of the slab decreases with the increase of water absorption, and the midspan displacement of the slab at 2 days, 3 days and 4 days has no significant difference. Although in the high humidity environment, the performance of the slab has decreased a lot, but the bending load has three times the weight of the plate, which is far greater than the 1.5 times of the plate weight required by the code. It can be concluded that the high humidity environment has great influence on the performance of ceramsite concrete slab, and more time, more impact. However, with time going on, the influence of high humidity environment on the slat will be stable to a certain range, then will not increase with time.

\subsection{Calculation of flexural capacity}

Mid span bending moment of simply supported beam under uniform load:

$$
\mathrm{M}=\frac{q l^{2}}{8} \#(1)
$$

In the above formula, M (unit: KN. m) - mid span bending moment of the simply supported beam, q (unit: $\mathrm{KN} / \mathrm{m}$ ) - uniformly distributed load applied to the simply supported beam, and 1 (unit: $\mathrm{m}$ ) - length of the simply supported beam.

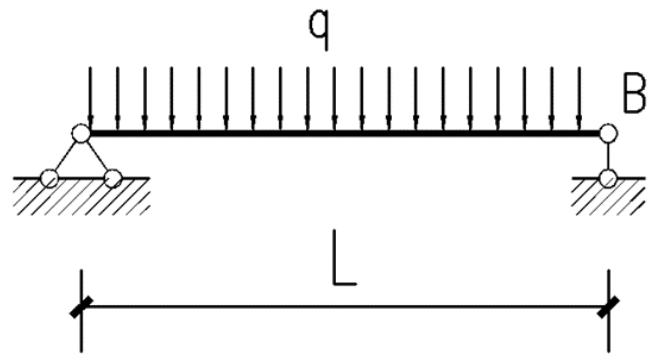

Figure 5. Schematic diagram of simply supported beam under uniform load

Mid span deflection of simply supported beam under uniform load:

$$
\omega=\frac{5 q l^{4}}{384 E I} \#(2)
$$

In the above formula, $\omega$ (unit: $\mathrm{mm}$ ) -mid span deflection of simply supported beam, $\mathrm{q}$ (unit: $\mathrm{KN} / \mathrm{m}$ ) -uniformly distributed load on simply supported beam, 1 (unit: $\mathrm{m}$ ) - length of simply supported beam, EI (unit: $\mathrm{KN} \cdot \mathrm{m} 2$ ) - bending rigidity of simply supported beam.

The air humidity has the greatest influence on the board after one day's curing in high humidity environment, and then the influence is small, therefore, three kinds of thickness plates are selected to be placed in the normal temperature and artificial environment warehouse for one day. Considering the plate material problem, the mid span displacement 
and mid span deflection of plates with the same thickness are approximately equal under the same environment. Therefore, the arithmetic mean value is calculated as the failure deflection of the plate with this thickness in this environment.

Table 4. Midspan failure deflection of various plates in different environment

\begin{tabular}{|c|c|c|}
\hline Plate type & environment & Failure deflection $(\mathrm{mm})$ \\
\hline $90 \mathrm{~mm}$ & normal atmospheric temperature & 1.78 \\
\hline $90 \mathrm{~mm}$ & High humidity & 1.70 \\
\hline $120 \mathrm{~mm}$ & normal atmospheric temperature & 1.89 \\
\hline $120 \mathrm{~mm}$ & High humidity & 1.87 \\
\hline $150 \mathrm{~mm}$ & normal atmospheric temperature & 1.80 \\
\hline $150 \mathrm{~mm}$ & High humidity & 1.76 \\
\hline
\end{tabular}

In order to make the ceramsite concrete lightweight partition board have enough safety reserves in the use process, it is also necessary to consider the quality difference of the slats in the production process, The failure deflection (denoted as $\omega$ ) of the slab is reduced to make it the recommended allowable deflection value, denoted as $[\omega] .50 \%$ of the mid span failure deflection of each type of slab is taken as the safety reserve, so the reduction factor of deflection is taken as 1.5 , the expression is as follows:

$$
\frac{\omega}{[\omega]}=1.5 \#(3)
$$

However, the above allowable deflection value is obtained when the length of ceramsite concrete slab is kept at $2 \mathrm{~m}$. However, in actual engineering, the length used is longer than it, or the length of slab is adjusted by cutting according to the site conditions, so the above allowable deflection is not generally applicable. Therefore, in order to improve the applicability of the allowable deflection, the allowable deflection value is adjusted to the relative allowable deflection value, and the ratio of the allowable deflection value $[\omega]$ to the length $\mathrm{L}$ of the slat is used to adjust the influence of the length change of the slat on the deflection. The expression of the relative allowable deflection value is: $([\omega]) / \mathrm{L}$.

The allowable deflections and relative allowable deflections of various ceramsite concrete slabs are shown in Table 5.

Table 5. Allowable deflection and relative allowable deflection of slab

\begin{tabular}{|c|c|c|c|}
\hline Plate type & environment & $\begin{array}{c}\text { Allowable } \\
\text { deflection }(\mathrm{mm})\end{array}$ & $\begin{array}{c}\text { Relative allowable } \\
\text { deflection }[\omega] / 1\end{array}$ \\
\hline $90 \mathrm{~mm}$ & normal atmospheric temperature & 1.19 & $0.60 \times 10^{-3}$ \\
\hline $90 \mathrm{~mm}$ & High humidity & 1.13 & $0.57 \times 10^{-3}$ \\
\hline $120 \mathrm{~mm}$ & normal atmospheric temperature & 1.26 & $0.63 \times 10^{-3}$ \\
\hline $120 \mathrm{~mm}$ & High humidity & 1.25 & $0.63 \times 10^{-3}$ \\
\hline $150 \mathrm{~mm}$ & normal atmospheric temperature & 1.20 & $0.60 \times 10^{-3}$ \\
\hline $150 \mathrm{~mm}$ & High humidity & 1.17 & $0.59 \times 10^{-3}$ \\
\hline
\end{tabular}

The actual bending stiffness of various plates per unit length is obtained by using the formula (2). In this paper, the calculation method of experimental data processing reference [9] is used. Therefore, the flexural rigidity of ceramsite concrete slabs in different environments is shown in Table 6.

Table 6. Bending stiffness of various plates in different environments

\begin{tabular}{|c|c|c|}
\hline Plate type & environment & Bending stiffness(kN/m) \\
\hline $90 \mathrm{~mm}$ & normal atmospheric temperature & 30.89 \\
\hline $90 \mathrm{~mm}$ & High humidity & 27.80 \\
\hline
\end{tabular}




\begin{tabular}{|c|c|c|}
\hline $120 \mathrm{~mm}$ & normal atmospheric temperature & 88.59 \\
\hline $120 \mathrm{~mm}$ & High humidity & 81.94 \\
\hline $150 \mathrm{~mm}$ & normal atmospheric temperature & 106.77 \\
\hline $150 \mathrm{~mm}$ & High humidity & 93.39 \\
\hline
\end{tabular}

The relative deflection of ceramsite concrete lightweight concrete partition board in the actual bearing process should be less than the relative allowable deflection, that is to say, the following formula should be satisfied:

$$
\frac{\omega}{l}=\frac{5 q l^{2}}{384 E I} \leq \frac{[\omega]}{l} \#(4)
$$

In the formula, the length $\mathrm{L}$ of the strip is determined according to the length of the strip

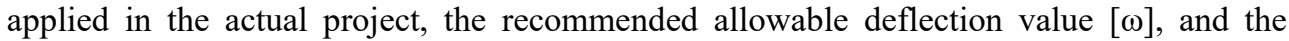
bending rigidity EI shall be selected according to the type of the strip used according to Table 7.

Table 7. Deflection value and bending rigidity value of slab in practical engineering

\begin{tabular}{|c|c|c|c|c|}
\hline $\begin{array}{l}\text { Plate } \\
\text { type }\end{array}$ & environment & length $(\mathrm{mm})$ & $\begin{array}{l}\text { Recommended } \\
\text { allowable } \\
\text { deflection }(\mathrm{mm})\end{array}$ & $\begin{array}{c}\text { Bending } \\
\text { stiffness } \\
(\mathrm{kN} / \mathrm{m})\end{array}$ \\
\hline $90 \mathrm{~mm}$ & $\begin{array}{c}\text { normal } \\
\text { atmospheric } \\
\text { temperature }\end{array}$ & 2600 & 1.56 & 30.89 \\
\hline $90 \mathrm{~mm}$ & High humidity & 2600 & 1.48 & 27.80 \\
\hline $120 \mathrm{~mm}$ & $\begin{array}{l}\text { normal } \\
\text { atmospheric } \\
\text { temperature }\end{array}$ & 2000 & 1.26 & 88.59 \\
\hline $120 \mathrm{~mm}$ & High humidity & 2000 & 1.25 & 81.94 \\
\hline $150 \mathrm{~mm}$ & $\begin{array}{l}\text { normal } \\
\text { atmospheric } \\
\text { temperature }\end{array}$ & 2900 & 1.74 & 106.77 \\
\hline $150 \mathrm{~mm}$ & High humidity & 2900 & 1.71 & 93.39 \\
\hline
\end{tabular}

\section{Vertical compression bearing test}

\subsection{Phenomenon}

In the compression loading test of prismatic block, cracks appear first in the upper half of the block, and then appear cracks or no cracks in the lower half, for a small number of test blocks, cracks appear first in the lower half of the test block, it is speculated that the reason is that the lower surface of the test block is not treated smooth and smooth, which leads to the greater load on the lower part of the test block, so it is the first to destroy. When the $90 \mathrm{~mm}$ and $120 \mathrm{~mm}$ blocks are damaged, only cracks are developed, however, when the $150 \mathrm{~mm}$ block is damaged, not only long and wide cracks appear, but also the upper surface of the test block is crushed, it is speculated that the reason is that the actual stress area of $150 \mathrm{~mm}$ test block is small, which leads to its low compressive strength and easy to be crushed. The compressive strength of prism specimens with different width and height is shown in Figure 6. 


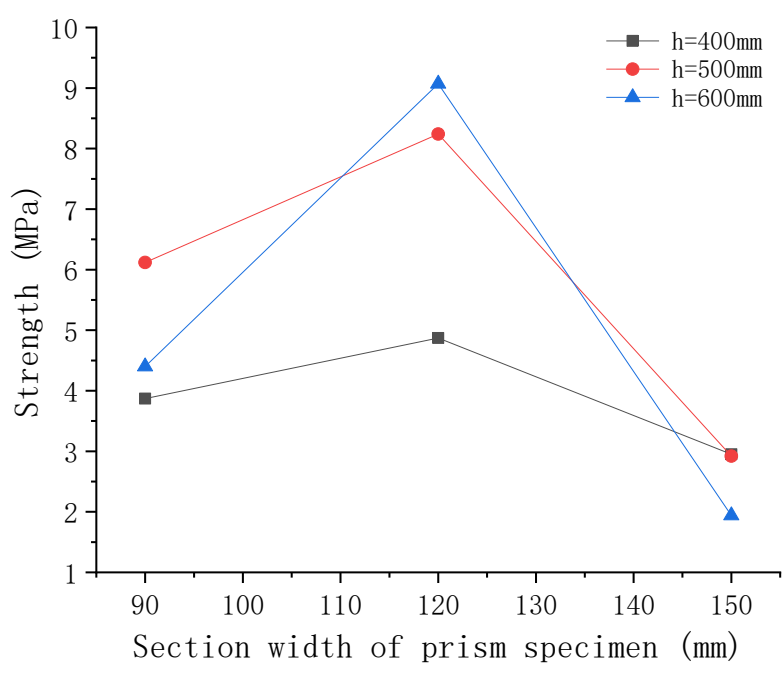

Figure 6. Compressive strength of prisms with different widths and heights

The hole diameter of $90 \mathrm{~mm}$ thick plate is $50 \mathrm{~mm}$, the hole area of prism compression surface accounts for $24.23 \%$, the actual compression area accounts for $75.77 \%$. The hole diameter of $120 \mathrm{~mm}$ thick plate is $70 \mathrm{~mm}$, the hole area of prism compression surface accounts for $26.71 \%$, the actual compression area accounts for $73.29 \%$. The hole diameter of the $150 \mathrm{~mm}$ thick plate is $90 \mathrm{~mm}$, the hole area of the prism is $28.26 \%$, the actual compressive area is $71.74 \%$. It can be seen from Figure 7 that the compressive strength of the specimen first increases and then decreases with the increase of the proportion of the hole area, when the hole area accounts for $26.71 \%$ of the compression surface, the compressive performance of the specimen is the best, when the ratio of compression area to hole area is about 3.1, the bearing capacity and axial compressive strength of the hollow prism are the best.

\subsection{Vertical compressive capacity}

In the practical engineering application, in order to prevent the wall panel damage caused by accidents, a part of the performance will be reserved as a safety reserve. In order to provide a certain basis for the use of this kind of ceramsite concrete slab in the actual project, the following will be based on the results of the compressive bearing test, using the reduction factor to reduce the compressive strength, and through the data to infer the reduction factor. Refer to the compressive strength formula in JGT 169-2005 lightweight battens for building partition walls:

$$
\mathrm{R}=\frac{P}{A} \#(5)
$$

In the above formula, $\mathrm{R}$ (unit: $\mathrm{MPa}$ ) - compressive strength of the specimen, $\mathrm{P}$ (unit: $\mathrm{KN}$ ) - failure load, A (unit:mm2) - Compressive area of the specimen.

In order to make the lightweight ceramsite concrete partition board have enough safety reserve in the use process, and also need to consider the quality difference of slats in the production process, the failure load $\mathrm{P}$ of prism test block is reduced to make it the recommended allowable failure load, which is recorded as $[\mathrm{P}] .50 \%$ of the mid span failure 
load of each type of slab is taken as the safety reserve, so the load reduction factor is taken as 1.5 , the expression is as follows:

$$
\frac{P}{[P]}=1.5 \#(6)
$$

In order to ensure the safety of the slab in actual use, the arithmetic mean value of the compressive strength of the prism test block of each thickness is calculated according to the formula $[\mathrm{P}]=\mathrm{AR} / 1.5$, which is taken as the compressive strength of the slab and the allowable compressive load of the whole slab is calculated.

Table 8. Values of vertical allowable load of slab in practical engineering

\begin{tabular}{|c|c|c|c|}
\hline Plate type & $\begin{array}{c}\text { Vertical compression } \\
\text { area }\left(\mathrm{mm}^{2}\right)\end{array}$ & $\begin{array}{c}\text { compressive } \\
\text { strength(MPa) }\end{array}$ & $\begin{array}{c}\text { Vertical allowable load of } \\
\text { slab(kN) }\end{array}$ \\
\hline $90 \mathrm{~mm}$ & 42955.5 & 4.53 & 129.73 \\
\hline $120 \mathrm{~mm}$ & 63309.0 & 7.39 & 311.90 \\
\hline $150 \mathrm{~mm}$ & 80391.5 & 2.37 & 127.02 \\
\hline
\end{tabular}

\section{Conclusion}

Through the bending bearing capacity test of the wall panel and the axial compression test of prism test block, the following points can be obtained:

(1) $80 \%$ of the high humidity environment will indeed reduce the bending capacity of the plate, and the bearing capacity of $90 \mathrm{~mm}, 120 \mathrm{~mm}$ and $150 \mathrm{~mm}$ plates will decrease by $13.6 \%, 9.1 \%$ and $19.4 \%$ respectively. The $120 \mathrm{~mm}$ plate is the least affected by high humidity environment because of its minimum water absorption.

(2) High humidity environment has great influence on the performance of ceramsite concrete slab, and the longer the time, the greater the influence. However, with time going on, the influence of high humidity environment on the slat will be stable to a certain range, and will not increase with time.

(3) According to the test data, the mechanical properties of $120 \mathrm{~mm}$ thick plate are better than those of $90 \mathrm{~mm}$ and $150 \mathrm{~mm}$ plate, so $120 \mathrm{~mm}$ thick plate should be selected as much as possible.

(4) The deflection and flexural rigidity of ceramsite concrete slab and the vertical allowable load of the slab are taken.

\section{Acknowledgements}

This paper is based upon work supported by postgraduate science and technology innovation project in Chongqing University of science and technology(No.YKJCX1920629).

\section{References}

1. Xu Chunyi, Xu Yiting, et al. Experimental study on flexural behavior of prefabricated ALC block wallboard with fiber grid [J]. New building materials, 2019, 46 (4): 55-58, 67.

2. Pan Guang Dong, Wang Jingfeng, et al. Experimental study and numerical analysis of cold-formed thin-walled steel light polymer composite wallboard [J]. Journal of Hefei University of technology, 2020,43 (6): 823-829. 
3. Zhu Wenxiang, Xu Jinfeng. Study on bending and thermal performance of new precast concrete thermal insulation wallboard [J]. New building materials, 2017,44 (12): 120-125.

4. Chen Boshan, Zhang Guowei, et al. Experimental and numerical simulation study on flexural behavior of autoclaved aerated concrete slabs $[\mathrm{J}]$. New building materials, 2018,45 (9): 61-65.

5. Zhou Xuejun, Wang Yue, et al. Study on mechanical properties of autoclaved ceramic powder aerated concrete self insulation wall panel [J]. Journal of Shandong Jianzhu University, 2020, 35 (3): 1-6.

6. Su Zheng, Cao Baozhu, et al. Study on flexural behavior of steel mesh truss EPS composite plate coated with POE cement mortar [J]. Concrete, 2020, (1): 155-159.

7. Wang Yue. Theoretical analysis and experimental study on mechanical properties of prefabricated autoclaved ceramic powder aerated concrete wallboard [D]. Shandong Jianzhu University, 2017.

8. Chen Bo. Study on bending and axial compression performance of fabricated light steel composite insulation exterior wall panel [D]. Nanchang University, 2019.

9. Bian Xiaofeng, Zhao Kezhong. Experimental study on flexural properties of fiber reinforced gypsum board [J]. Journal of Shandong Jianzhu University, 2009, 24 (3): 256-260. 